\title{
Gradhiva
}

GRADHI

Revue d'anthropologie et d'histoire des arts

$7 \mid 2008$

Le possédé spectaculaire

\section{Le possédé spectaculaire}

Possession, théâtre et globalisation

Erwan Dianteill et Bertrand Hell

\section{CpenEdition}

Journals

Édition électronique

URL : http://journals.openedition.org/gradhiva/996

DOI : 10.4000/gradhiva.996

ISSN : 1760-849X

Éditeur

Musée du quai Branly Jacques Chirac

Édition imprimée

Date de publication : 15 mai 2008

Pagination : 4-5

ISBN : 978-2-915133-86-8

ISSN : 0764-8928

Référence électronique

Erwan Dianteill et Bertrand Hell, « Le possédé spectaculaire », Gradhiva [En ligne], 7 | 2008, mis en ligne le 10 décembre 2008, consulté le 21 septembre 2020. URL : http://journals.openedition.org/gradhiva/ 996 ; DOI : https://doi.org/10.4000/gradhiva.996

(c) musée du quai Branly 


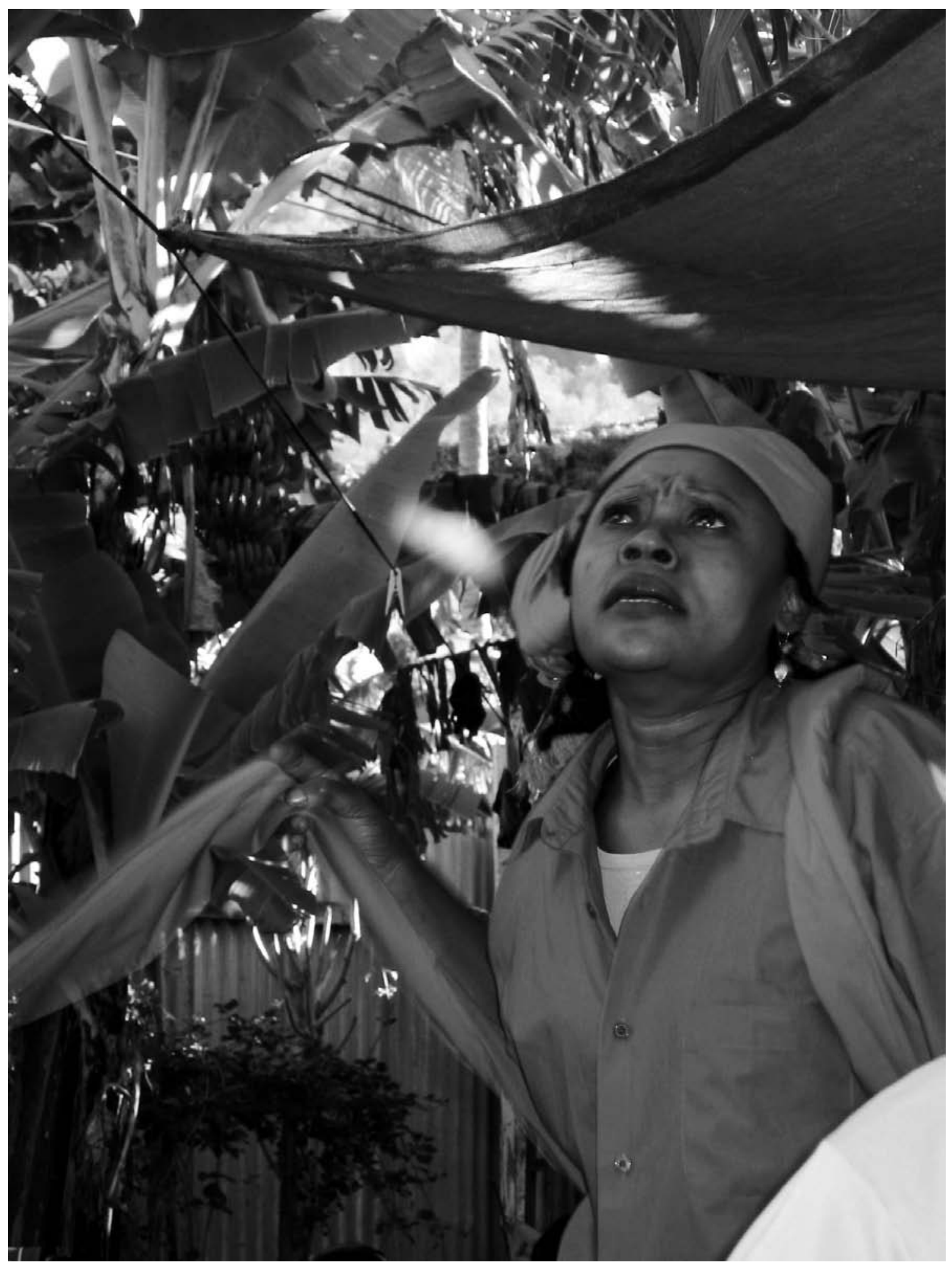

Fig.1 Femme possédée par son esprit patros Djalud. Mayotte, juillet 2003. Photo Bertrand Hell. 


\title{
Le possédé spectaculaire. Possession, théâtre et globalisation
}

\author{
Introduction
}

$\grave{\mathrm{A}}$

la fin des années 1950, certaines questions majeures de l'anthropologie de la possession ont été formulées par Roger Bastide, Michel Leiris et Alfred Métraux. La question centrale était alors celle de la possibilité du partage entre authenticité de la transe et travail d'acteur. Ces trois anthropologues ont en commun de rejeter l'approche psychiatrique de la possession, qui conçoit la transe comme un état psychopathologique ou une libération incontrôlée de pulsions; néanmoins Bastide, Leiris et Métraux accentuent à des degrés différents l'aspect joué ou non de la possession. Dès 1938 (Journal de Psychologie), Leiris anticipait les développements sur le "vestiaire de personnalités " qui aboutiront à la publication de La Possession et ses aspects théâtraux chez les Éthiopiens de Gondar. Bastide plaide plutôt pour l'authenticité de la possession dans son ouvrage Le Candomblé de Bahia, le jeu d'acteur étant pour lui un signe de dégénérescence d'une transe originelle posée comme authentique. La possession peut être réglée et véridique, tel est le point de vue de Bastide, perspective que l'on voit exposée à nouveau dans la lettre publiée dans ce numéro. Quant à Métraux, il tangue entre l'empathie qui porte à donner crédit à la véracité de la possession et l'ironie voltairienne qui n'y voit qu'une supercherie. Comme l'écrit Pierre Verger, "le livre de Métraux est un savant équilibre entre ces deux attitudes », entre l'enthousiasme et l'ironie.

On peut aujourd'hui reprendre ce débat en des termes nouveaux, pour au moins deux raisons. La première raison est d'ordre épistémologique. C'est une évidence : les sciences sociales d'aujourd'hui ne sont plus celles des années 1950. Les données ethnographiques sont plus abondantes, les théories se sont renouvelées. De nouveaux courants sont apparus et se sont développés récemment, en particulier les approches cognitives, pragmatiques, les gender studies, les performance studies ainsi que la théorie littéraire. Ces perspectives permettent d'éclairer la possession de façon nouvelle en s'intéressant en particulier à la puissance émotionnelle de la fiction créatrice et de l'imagination active. Un surréalisme en action : l'idée avancée par André Breton dès son premier contact avec le vaudou haïtien est désormais familière aux anthropologues. La seconde est liée aux transformations du monde contemporain auxquelles n'échappent pas les cultes de possession. Les auteurs qui participent au dossier traitent la question de la possession rituelle dans différents pays (Maira Muchnik traite de l'Argentine, Erwan Dianteill du Brésil, Bertrand Hell de Mayotte, Deborah Kapchan du Maroc), qui ont néanmoins en commun de ne plus être des sociétés " traditionnelles " (si ce fut jamais le cas). La mise en spectacle, la marchandisation de la culture, l'accélération et la généralisation de la communication électronique : autant de processus qui caractérisent la surmodernité et ont des effets notables sur les religions extatiques qui nous intéressent. Les modalités actuelles du contact direct avec le sacré sont riches d'enseignement sur l'éminente plasticité de ces états d'effervescence collective, qui sont capables, selon Émile Durkheim, de donner l'impression à l'homme « d'être devenu un être nouveau ». Quels sont les jeux spéculaires d'identité à l'œuvre lors d'une séance de possession? Quelles sont les modalités de communication entre les hommes et les esprits ? Comment se fait le lien entre la dramaturgie propre aux cultes de possession et la mise en spectacle marchande caractéristique du capitalisme global? Telles sont quelques-unes des questions abordées dans ce dossier. 